04

\title{
Некоторые особенности спектра рентгеновского излучения микропинча при одноимпульсной регистрации
}

\author{
(C) А.Н. Долгов ${ }^{1}$, Н.А. Клячин ${ }^{2}$, Д.Е. Прохорович 1,2 \\ ${ }^{1}$ Всероссийский научно-исследовательский институт автоматики \\ им. Н.Л. Духова, Москва, Россия \\ ${ }^{2}$ Национальный исследовательский ядерный университет „МИФИ“, \\ Москва, Россия \\ E-mail: alnikdolgov@mail.ru
}

Поступило в Редакцию 25 июля 2018 г.

Описаны методика и результаты исследования линейчатого спектра рентгеновского излучения микропинчевого разряда. В качестве детектора излучения использовалась малогабаритная диффузионная камера оригинальной конструкции.

DOI: $10.21883 /$ PJTF.2018.23.47006.17474

Цель описанных в настоящей работе экспериментов состояла в регистрации характеристического спектра излучения плазмы железа в сильноточном разряде типа $Z$-пинч с использованием в качестве детектора малогабаритной диффузионной камеры [1]. В сильноточных разрядах типа $Z$-пинч, реализуемых в среде тяжелых элементов, наблюдается формирование уникального объекта: микропинча, часто называемого „горячей точкой“, - локализованной области размером менее $0.1 \mathrm{~mm}$ горячей $\left(T_{e} \approx 1 \mathrm{keV}\right)$ плотной $\left(n_{e} \approx 10^{22} \mathrm{~cm}^{-3}\right)$ плазмы [2].

Одним из самых продуктивных методов диагностики плотной горячей плазмы несомненно является дифракционная спектроскопия рентгеновского излучения. При исследовании плазмы, обладающей значительным разбросом параметров от импульса к импульсу, важна возможность регистрировать спектр излучения в единичном импульсе. Диффузионная камера показала необходимые для этого высокую эффективность регистрации квантов с энергиями до нескольких килоэлектронвольт и достаточно высокое пространственное разрешение (доли миллиметра) [3]. 


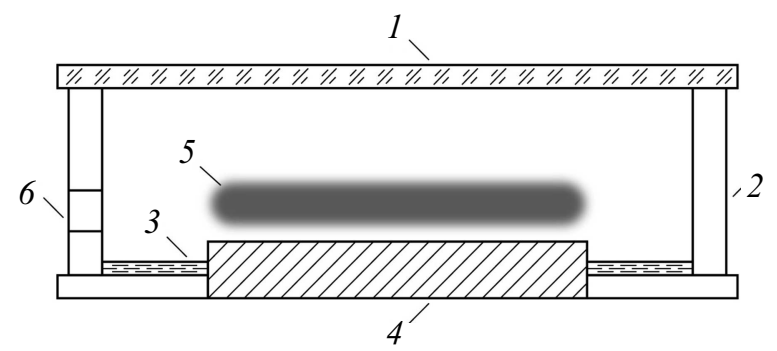

Рис. 1. Конструкция диффузионной камеры. 1 - стеклянное окно (крышка), 2 - боковая диэлектрическая стенка, 3 - испаритель, 4 - охлаждаемое дно, 5 - чувствительный слой, 6 - входное окно для ионизирующего излучения.

В наших экспериментах использовалась диффузионная камера следующей конструкции (рис. 1). Камера имеет вертикальные стенки, выполненные из диэлектрика, обладающего низкой теплопроводностью, горизонтальное стеклянное окно (крышка) и массивное металлическое дно, снабженное каналами для транспортировки хладагента. В периферийной части дна камеры расположен испаритель - пропитанная рабочей жидкостью (этиловый спирт) ткань при температуре, близкой к комнатной. Температура дна камеры примерно на $80^{\circ} \mathrm{C}$ ниже температуры крышки камеры, что обеспечивается присутствием хладагента сжиженного азота. Рабочая среда детектора - смесь воздуха при атмосферном давлении и паров этилового спирта. Насыщенные пары спирта диффундируют в область низких температур, постепенно становясь все более пересыщенными. В результате вблизи дна формируется горизонтальный чувствительный слой парогазовой смеси - область диаметром $100 \mathrm{~mm}$ и толщиной примерно $3 \mathrm{~mm}$ с пересыщением, достаточным для конденсации пара на ионах. Прошедшая через чувствительный слой заряженная частица оставляет на своем пути цепочку центров конденсации - ионов, на которых вырастают капли размером до $30 \mu \mathrm{m}$. Заряженными частицами в нашем случае являются вторичные электроны, рождающиеся при прохождении квантов рентгеновского излучения через парогазовую смесь. Пучок исследуемого коротковолнового излучения плазмы направлялся в чувствительный слой диффузионной камеры после отражения от диспергирующего кристалла. С целью изучения спектрального состава рентгеновского излучения разряда в области $K$-спектра железа в диапазоне $0.17-0.20 \mathrm{~nm}$ использовался фокусирую-

Письма в ЖТФ, 2018, том 44, вып. 23 
щий спектрограф по схеме Иоганна на кристалле $\operatorname{LiF}(2 d=0.4026 \mathrm{~nm})$ с радиусом изгиба $300 \mathrm{~mm}$ и дисперсией $10^{-3} \mathrm{~nm} / \mathrm{mm}$. Диффузионная камера располагалась таким образом, чтобы круг Роуланда проходил внутри ее рабочего объема в плоскости чувствительного слоя. Входное окно в стенке диффузионной камеры, предназначенное для транспортировки регистрируемого излучения, шириной $50 \mathrm{~mm}$ и высотой $20 \mathrm{~mm}$ закрывалось пленкой лавсана толщиной $12 \mu \mathrm{m}$. Треки освещались импульсной лампой с временем свечения $1 \mathrm{~ms}$ и задержкой относительно момента разряда $300 \mathrm{~ms}$ и фиксировались фотоаппаратом. В дальнейшем при обработке снимков производилось их фотометрирование.

Источником рентгеновского излучения являлась плазма низкоиндуктивной сильноточной вакуумной искры [3]. Разряд осуществлялся в вакуумной камере, откачанной до $10^{-5}$ Torr, в продуктах эрозии электродов разрядного устройства. Электроды (анод конический, катод плоский) были изготовлены из стали марки Ст. 3 и 12Х18Н10Т соответственно. Таким образом, основным элементом, присутствующим в плазме разряда, было железо. Разряд инициировался инжекцией форплазмы в межэлектродное пространство от вспомогательного источника. Рентгеновское излучение выводилось за пределы вакуумной камеры через вакуумноплотное бериллиевое окно толщиной $100 \mu \mathrm{m}$. Достигаемый в разряде ток составлял $120 \mathrm{kA}$ при времени нарастания тока $1 \mu \mathrm{s}$. Предварительно выполненное обскурографирование плазмы разряда показало, что, во-первых, в спектральном диапазоне $\lambda<0.4 \mathrm{~nm}$ наиболее ярким источником излучения является микропинч, а вовторых, в условиях проводимого эксперимента сжатие плазмы разряда собственным магнитным полем приводит к формированию микропинча с вероятностью около $90-95 \%$.

Результаты наших исследований можно суммировать следующим образом.

В отсутствие регистрируемого диффузионной камерой спектра в диапазоне $K_{\alpha}-K_{\beta}$ железа нет и изображения микропинча на фотоэмульсионном детекторе камеры-обскуры. И наоборот, отсутствие изображения микропинча на обскурограмме однозначно означало отсутствие регистрируемого диффузионной камерой спектра излучения в указанном выше диапазоне.

В виде отдельных линий в спектре удалось зарегистрировать характеристическое излучение $K_{\alpha}$ и $K_{\beta}$ железа и излучение многозарядных ионов FeXVIII-FeXXV. Излучение водородоподобного иона железа

Письма в ЖТФ, 2018, том 44, вып. 23 
FeXXVI зарегистрировать не удалось. Линии излучения низкозарядных ионов сливались и не были различимы. Идентификация наблюдаемых в спектре линий характеристического излучения и линий излучения многозарядных ионов осуществлялась путем сравнения денситограмм зарегистрированных нами спектров с денситограммами спектров излучения микропинчевых разрядов в плазме железа, приводимыми в научной литературе авторами, качество работ которых не может вызывать сомнений $[4,5]$. Форма регистрируемого спектра варьируется от разряда к разряду.

Возникновение линии $K_{\alpha}$ в спектре регистрируемого излучения всегда сопровождается появлением излучения иона FeXVIII и изображения микропинча на обскурограмме.

Регулярно наблюдается смещение от среднего положения, определяемого по положению пиков, соответствующих $K_{\alpha}$ и $K_{\beta}$, линий излучения ионов FeXXIII-FeXXV. Величина смещения составляет примерно $(2-3) \cdot 10^{-4} \mathrm{~nm}$.

Если на прописи спектра изображения, отвечающие излучению $K_{\alpha}$-линии и линии иона FeXVIII, разделены глубоким провалом, то излучение ионов наиболее высоких зарядностей FeXXIII-FeXXV не регистрируется (рис. 2, $a$ ).

Излучение линии $K_{\beta}$ наблюдается далеко не в каждом разряде, а только примерно в $40 \%$ случаев. Наличие в спектре излучения ионов наиболее высоких зарядностей FeXXIII-FeXXV из числа зарегистрированных не гарантирует появления в спектре излучения линии $K_{\beta}$ (рис. $2, b$ и $c$ ).

Появление в спектре линий ионов FeXXIII-FeXXV обычно сопровождается возрастанием вклада излучения ионов FeXIX-FeXXII.

При сравнении спектров, зарегистрированных с помощью диффузионной камеры в единичном разряде, нетрудно увидеть их значительное отличие от спектра, зарегистрированного с использованием рентгеновской фотопленки в качестве детектора излучения в серии из 50 разрядов (рис. 3).

На основании экспериментов можно сделать следующие выводы.

Формирование микропинча однозначно связано с образованием многозарядных ионов в плазме разряда. Наблюдаемому смещению от среднего положения линий FeXXIII-FeXXV соответствует исходя из допплеровского механизма смещения радиальная скорость ионов порядка $(2-3) \cdot 10^{5} \mathrm{~m} / \mathrm{s}$ или кинетическая энергия порядка $10-20 \mathrm{keV}$.

3 Письма в ЖТФ, 2018, том 44, вып. 23 

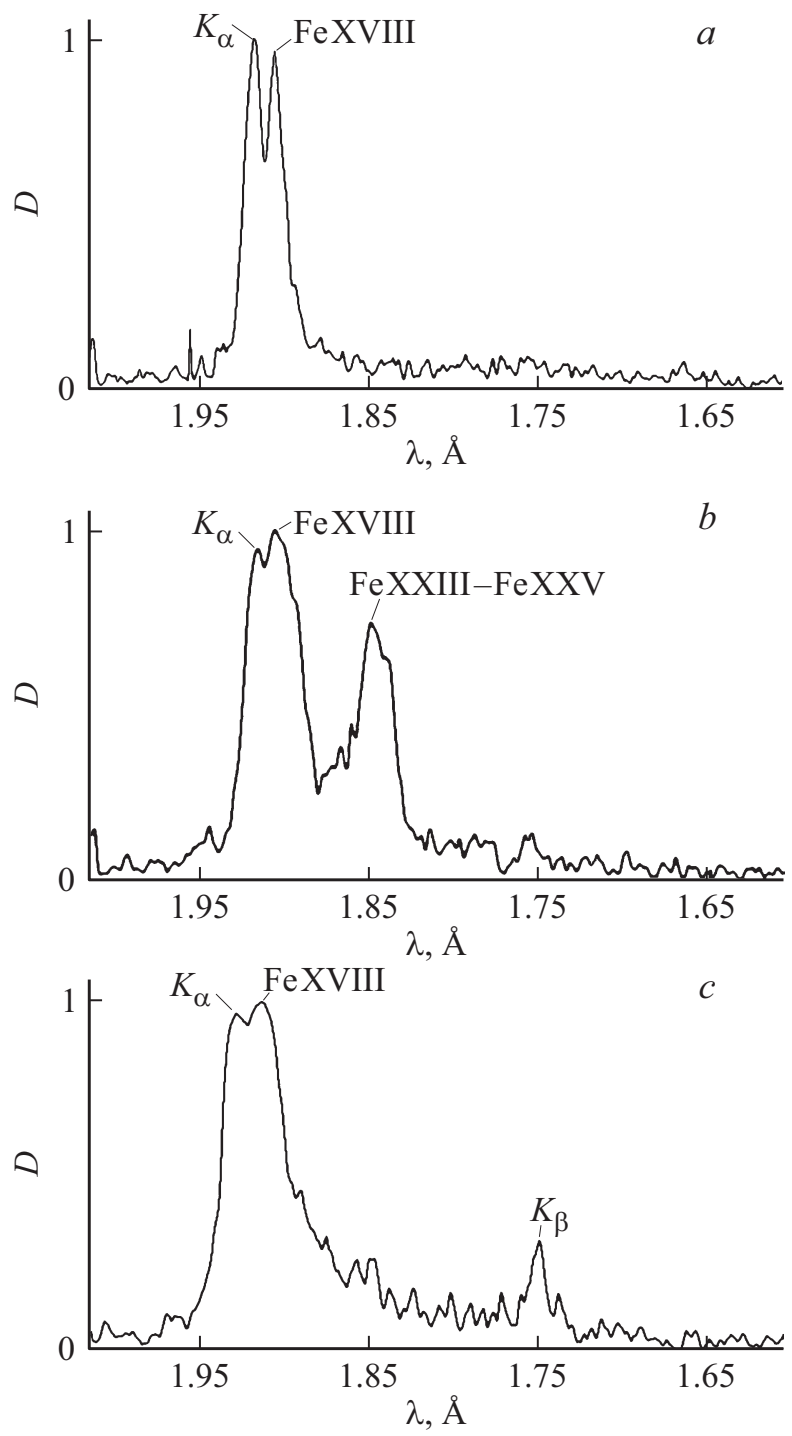

Рис. 2. Прописи спектров рентгеновского излучения, зарегистрированных с помощью диффузионной камеры в единичном разряде. Пояснение в тексте.

Письма в ЖТФ, 2018, том 44, вып. 23 


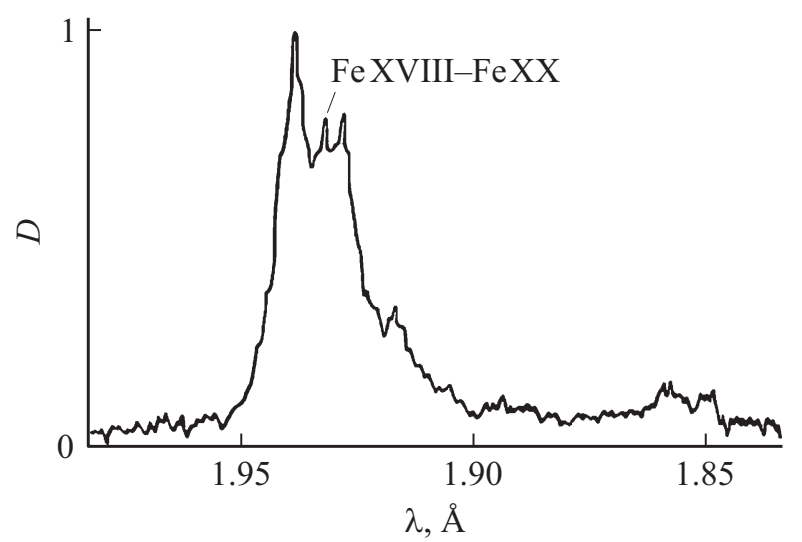

Рис. 3. Пропись спектра рентгеновского излучения, зарегистрированного с помощью рентгеновской фотопленки в серии из 50 разрядов.

Наблюдение в спектре излучения микропинча линий ионов по крайней мере 17-й зарядности свидетельствует о том, что достижение именно данной кратности ионизации ионной компоненты плазмы в перетяжке токового канала делает возможным формирование микропинча. Теоретическая модель радиационного сжатия плазмы в микропинчевом разряде указывает на то, что как раз в момент появления в плазме железа ионов FeXVIII происходит перемена режима сжатия: переход от магнитогидродинамического к радиационному режиму [6]. В этом можно усмотреть хорошее совпадение предсказаний теоретической модели и результатов эксперимента.

Экспериментальные результаты, указывающие на усиление вклада в регистрируемый спектр излучения ионов FeXIX-FeXXII с появлением в спектре излучения ионов FeXXIII-FeXXV, также свидетельствуют в пользу выводов модели радиационного сжатия. Согласно модели, для более глубокого сжатия, отличающегося большей достигаемой кратностью ионизации атомарных частиц, требуется большее число частиц в микропинче на начальной стадии сжатия. Соответственно усиливается вклад в спектр излучения ионов, существующих в микропинче на начальной стадии сжатия.

Появление в спектре излучения ионов FeXXIV-FeXXV при наличии линии иона FeXVIII, согласно модели радиационного сжатия,

$3^{*}$ Письма в ЖТФ, 2018, том 44, вып. 23 
является необязательным. Модель предсказывает, что ионы высокой зарядности FeXXIV-FeXXV могут появиться на стадии развала микропинча. Одновременно скачок сопротивления токового канала должен приводить к скачку напряженности электрического поля и ускорению электронной компоненты.

Можно усмотреть некоторое противоречие между результатами эксперимента и предсказаниями модели в том, что появление линий $K_{\alpha}$ и излучения иона FeXVIII не всегда сопровождается появлением в спектре линии $K_{\beta}$ и линий излучения ионов FeXXIII-FeXXV, так как появление линии $K_{\alpha}$ (и $K_{\beta}$ ) связано с рождением быстрых частиц, т.е. развитие аномального сопротивления и ускорительных процессов может происходить уже на стадии перехода к радиационному сжатию, а не только на стадии развала микропинча. Однако этот факт можно легко объяснить, если принять, что характеристическое излучение возникает под действием быстрых электронов в основном в плазме микропинча. В этом случае отсутствие линии $K_{\beta}$ может означать, что на пути пучка электронов не оказалось ионов с кратностью ионизации ниже 16-й, а именно такая ситуация складывается в момент перехода к радиационному сжатию.

Таким образом, регулярное присутствие в спектре излучения линии $K_{\beta}$ может свидетельствовать об опережающем развитии ускорительных процессов для электронной компоненты по отношению к процессу распада микропинча.

\section{Список литературы}

[1] Клячин Н.А., Ляпидевский В.К., Максимов В.Ю. // ПТЭ. 1991. № 2. С. 77-79.

[2] Месяи Г.А., Шелковенко Т.А., Иваненков Г.В., Агафонов А.В., Савинов С.Ю., Пикуз С.А., Тиликин И.Н., Ткаченко С.И., Чайковский С.А., Ратахин Н.А., Федощак В.Ф., Орешкин В.И., Федюнин А.В., Русских А.Г., Лабецкая Н.А., Артемов А.П., Хаммер Д.А., Синарс Д.Б. // ЖЭТФ. 2010. Т. 138. В. 3. С. $411-$ 420.

[3] Веретенников В.А., Клячин Н.А., Крохин О.Н., Ляпидевский В.К., Семенов О.Г. // Физика плазмы. 1988. Т. 14. № 8. С. 993-998.

[4] Гольи Э.Я., Житник И.А., Кононов Э.Я., Мандельштам С.Л., Сидельников Ю.В. // ДАН СССР. 1975. Т. 22. В. 3. С. 560-563.

[5] Кононов Э.Я., Кошелев К.Н., Сидельников Ю.В. // Физика плазмы. 1977. Т. 3. № 3. C. 663-673.

[6] Вихрев В.В., Иванов В.В., Кошелев К.Н. // Физика плазмы. 1982. Т. 8. № 6. C. 1211-1219.

Письма в ЖТФ, 2018, том 44, вып. 23 